IZA DP No. 7556

Modeling Income Dynamics for Public Policy Design: An Application to Income Contingent Student Loans

Tim Higgins

Mathias Sinning

August 2013 


\title{
Modeling Income Dynamics for Public Policy Design: An Application to Income Contingent Student Loans
}

\author{
Tim Higgins \\ Australian National University \\ Mathias Sinning \\ Australian National University, \\ $R W I$ and IZA
}
Discussion Paper No. 7556
August 2013

IZA
P.O. Box 7240
53072 Bonn
Germany

\author{
Phone: +49-228-3894-0 \\ Fax: +49-228-3894-180 \\ E-mail: iza@iza.org
}

\begin{abstract}
Any opinions expressed here are those of the author(s) and not those of IZA. Research published in this series may include views on policy, but the institute itself takes no institutional policy positions. The IZA research network is committed to the IZA Guiding Principles of Research Integrity.

The Institute for the Study of Labor (IZA) in Bonn is a local and virtual international research center and a place of communication between science, politics and business. IZA is an independent nonprofit organization supported by Deutsche Post Foundation. The center is associated with the University of Bonn and offers a stimulating research environment through its international network, workshops and conferences, data service, project support, research visits and doctoral program. IZA engages in (i) original and internationally competitive research in all fields of labor economics, (ii) development of policy concepts, and (iii) dissemination of research results and concepts to the interested public.
\end{abstract}

IZA Discussion Papers often represent preliminary work and are circulated to encourage discussion. Citation of such a paper should account for its provisional character. A revised version may be available directly from the author. 
IZA Discussion Paper No. 7556

August 2013

\section{ABSTRACT}

\section{Modeling Income Dynamics for Public Policy Design: An Application to Income Contingent Student Loans*}

This paper studies the importance of dynamic earnings modeling for the design of income contingent student loans (ICLS). ICLs have been shown to be theoretically optimal in terms of efficiency in the presence of risk aversion, adverse selection and moral hazard, and have attractive equity properties. Recognition of their benefits has led to their adoption for tertiary education tuition fees in countries including Australia, New Zealand, and the UK. Since the design of ICLs relies on the prediction of the underlying costs, we explore the extent to which the complexity of earnings modeling affects the estimation of loan subsidies. The use of Australian data allows us to compare our simulated debt repayments to actual repayments under the Australian Higher Education Contribution Scheme (HECS). Our findings reveal that the complexity of earnings modeling has considerable implications for the calculation of loan subsidies.

JEL Classification: H81, I22, C15

Keywords: educational finance, dynamic stochastic modeling, panel data, income contingent loans

Corresponding author:

Mathias Sinning

Research School of Economics (RSE)

HW Arndt Building 25a

Australian National University

Canberra ACT 0200

Australia

E-mail: mathias.sinning@anu.edu.au

\footnotetext{
* This paper uses confidentialized unit record file data from the HILDA survey. The HILDA Project was initiated and is funded by the Department of Families, Community Services, and Indigenous Affairs (FaCSIA) and is managed by the Melbourne Institute of Applied Economic and Social Research (MIAESR). The findings and views reported in this paper, however, are those of the authors and should not be attributed to FaCSIA or MIAESR. We thank Bruce Chapman, Glenn Withers, and the participants of the ANU-DPU Conference on Education and Labour Market Outcomes for helpful comments and suggestions and gratefully acknowledge the support of the Australian Research Council (LP1102200496).
} 


\section{Introduction}

An important and challenging task in the formulation of policy design is to ensure that decisions are informed by accurate cost projections. Many areas of policy, including for example income tax, social security and retirement scheme design, require accurate predictions of future individual incomes. Without such predictions, there is a risk of misstating the tax burden and consequent labour market effects, as well as the magnitude of individual consumption and savings, including pension scheme contributions and wealth accrual. It is also important that incomes are accurately predicted in the design and assessment of education policy, particularly if the policy design is dependent on expected repayment burdens, loan repayments, or returns to education.

An obvious area where accurate prediction of future assessable incomes is critical is in the design and analysis of income contingent loans (ICLs) for university students. ICLs in the context of university fees have been shown to be theoretically optimal in terms of efficiency in the presence of risk aversion, adverse selection and moral hazard (Gary-Bobo and Trannoy, 2013). As a policy instrument, ICLs address student liquidity constraints, and have clear advantages in terms of equity and provision of access over graduate taxes. In ICL design, future assessable incomes are used to calculate a number of relevant quantities, including the rate of repayment of a university graduate and - depending on the design of the scheme - the resulting costs to taxpayers. Since ICL costs are sensitive to future assessable incomes, the empirical strategy that is employed to model future assessable incomes has considerable implications for the instrument design.

Research on the application and costing of ICL typically utilizes conventional earnings models based on single or pooled cross-sectional data (see, e.g., Chapman and Lounkaew, 2010), however, this ignores important aspects of earnings and employment dynamics. Models of earnings dynamics were first proposed in the literature in the late 1970s to capture life cycle dynamics (Lillard and Willis, 1978), and have since been

used extensively in the exploration of earnings inequality (Guvenen, 2009; Moffitt and Gottschalk, 2002; Baker and Solon, 2003; Cappellari, 2004; Haider, 2001) and in mi- 
crosimulation modeling for the projection of social security and public pension schemes, long-term care, social welfare and taxation policy (O'Donoghue, 2001; Caldwell, 1996; Holmer et al., 2010; Toder et al., 2000; Harris and Sabelhaus, 2003). Indeed, the limitations of static earnings functions in the investigation of higher education policy have been recognised by some, with Migali (2012) incorporating stochastic variation in the growth rate of graduate earnings, and dynamic microsimulation of lifetime earnings having been applied to the modelling of higher education finance and ICLs specifically (e.g., Harding, 1995; Flannery and O’Donoghue, 2011). What has not been explored to date, however, is the extent to which ICL policy conclusions are sensitive to the earnings model assumptions used.

In this paper, we study the extent to which the complexity and realism of labor force transition assumptions and earnings models affect ICL repayments and costs, using a sample of university graduates from the Household, Income and Labour Dynamics in Australia (HILDA) Survey. The use of Australian data allows us to compare simulated debt repayments to actual repayments under the Australian Higher Education Contribution Scheme (HECS). In order to model earnings dynamics, we combine a model of labor force transitions with a model of earnings conditional on labor force state. We further compare our results obtained from a static (cross-sectional) model to those of a dynamic panel model that allows for permanent and transitory shocks.

Our empirical analysis is related to a growing literature that examines the covariance structure of earnings and distinguishes between transitory and permanent components of earnings (examples include Lillard and Willis, 1978; MaCurdy, 1982; Abowd and Card, 1989; Dickens, 2000; Meghir and Pistaferri, 2004; Kalwij and Alessie, 2007). Our work builds on Higgins (2011) who provides a detailed discussion of the technical issues related to the implications of earnings model complexity in the context of ICL modeling. Our analysis contributes to the literature by using a sample of university graduates to compare alternative empirical approaches and apply predictions to HECS to investigate the extent to which the choice of the underlying empirical model affects the prediction of loan subsidies. 
HECS constitutes an excellent example for the purpose of our empirical analysis. The Scheme was introduced in 1989 to finance tuition fees of Australian university students. HECS was designed to address the problem of student credit constraints, while providing insurance to mitigate the risks associated with university participation. Like a graduate tax, an income contingent loan overcomes the private market failures from asymmetric information and lack of physical collateral that are the central problems when offering loans for human capital investments. However, as an income contingent loan, HECS is characterized by two important features (Chapman, 2006). First, the scheme provides default insurance because those with incomes below a particular threshold do not have to repay, and there is debt forgiveness on death of the debtor. Second, the scheme ensures consumption smoothing because repayments depend on current income and, unlike graduate taxes, the present value of repayments is limited to the original debt plus interest (that is, an ICL is debt finance as opposed to equity finance).

The cost to the taxpayer for a risk-sharing ICL scheme such as HECS arises due to administrative costs, and due to non-repayment of debt among some debtors as a consequence of default insurance and debt being written off on death. In Australia costs also arise in the form of interest subsidies, because outstanding debt is indexed at a rate of growth in the Consumer Price Index (CPI) which is less than the government's cost of borrowing. ${ }^{1}$ That is, debtor's who repay their total loan will receive an interest subsidy because of the time lag between borrowing and repayment. In 2012, the total nominal value of outstanding debt of HECS-HELP was $\$ 26.3$ billion (Norton, 2013). The percentage of the outstanding debt not expected to be repaid (DNER) was about $23.6 \%$ ( $\$ 6.2$ billion), representing the sum of the debt write-off and interest subsidies.

Of particular interest is how estimates of the total subsidy differ under different labor force and earnings models. In addition to providing information on the implication of model choice and development on existing ICL scheme costs, the results are of importance when designing new ICL schemes. In particular, cost recovery of loan

\footnotetext{
${ }^{1}$ Historically, the Australian government cost of borrowing (being the long-term government bond rate) over the last decade has averaged $5.5 \%$ nominal, representing a real rate of approximately $3 \%$.
} 
outlays requires applying an indexation rate that covers the risk of loan non-repayment (the 'cohort risk premium'). Understanding how labor force and earnings model choice affect estimation of the cohort risk premium will mitigate poor scheme design.

We find that the results obtained from static and dynamic models are quite different. We obtain repayment and debt predictions under the assumption that, firstly, earnings variability manifests predominantly as temporary shocks, and secondly, that earnings variability is highly persistent. We compare these results with the case when both temporary and permanent variation and shocks are incorporated. We further examine the implications of considering labor force dynamics, and we demonstrate that ignoring dynamic aspects may severely bias the prediction of outstanding debts. We also show that outstanding debt levels of male university graduates dissipate much faster than those of female graduates, revealing a relatively low repayment capacity among female

graduates. Finally, we demonstrate that ignoring dynamic aspects of earnings and labor force modeling has severe implications for the calculation of subsidies and the design of income contingent student loans. It is hoped that recognition of this result will lead to greater adoption of dynamic earnings processes in the modelling of ICL, thereby improving the accuracy of policy conclusions and comparisons.

The remainder of the paper is organized as follows. Section 2 describes the data used in our empirical analysis and presents some descriptive evidence. Our empirical strategy is explained in Section 3. Section 4 discusses our empirical findings. Section 5 concludes.

\section{Data and Descriptive Analysis}

Our empirical analysis employs data from the Household, Income and Labour Dynamics in Australia (HILDA) Survey for the years 2001-2011. The Survey collects information about economic and subjective wellbeing, labor market dynamics, and family dynamics. In 2001, the Survey included 7,682 households and 19,914 individuals. The interviews are conducted annually with all adult members of each household and panel members 
are followed over time.

The models described in Section 3 were developed and parameterized through analysis of the sample of university graduates aged 22-65 years. The models developed were then applied to a sample of graduates aged 22-35 years in 2001 to predict HECS repayments. This is described in more detail in Section 3. We further employ a sample of university graduates aged 22-55 years to provide a description of earnings and labor force mobility in the current section. ${ }^{2}$

The income measure that is used to calculate assessable income is equal to taxable income, plus any reduction in taxable income due to rental loss, plus fringe benefits and exempt foreign employment income. ${ }^{3}$ We ignore fringe benefits and exempt foreign employment income when modeling ICL repayments because their contribution to overall income is relatively small (ABS, 2006). Taxable income mainly includes wages and salaries, business earnings, investment returns, and government pensions and allowances. Since the main part of taxable income of a typical ICL debtor comes from wages and salaries (Higgins, 2011), our definition of earnings is restricted to financial year gross wages and salaries in real 2011 AUS\$.

We further distinguish four labor force states: full-time employment, part-time employment, unemployment, and not in the labor force. Using these labor force states to model labor force transitions allows us to model earnings conditional on labor force state.

For the purpose of descriptive analysis, and to motivate the subsequent modeling, we study earnings mobility in HILDA by decomposing male and female earnings from wage and salary into quintiles, and measure the proportion of individuals within each quintile in a particular year that remain in the same quintile, or move to other quintiles in the following year. Using a sample of 22-55 year old university graduates, we calculate mobility rates across earnings quintiles over two consecutive years for the entire period 2001-2011 and then take the average of all year pairs to calculate average mobility rates.

\footnotetext{
${ }^{2}$ We drop employed persons from all samples if their number of usual hours worked is unknown. We create a balanced panel based on respondents observed in 2001 (who may drop out of the panel before 2011). The sample of 22-55 year olds includes 16,047 person-year observations.

${ }^{3}$ See http://www.gotouni.gov.au .
} 
These rates, which are presented in Table 1, indicate that the earnings of employed men are quite persistent but somewhat less persistent among women (both full- and part-time employed). Table 1 reveals mobility rates between two neighboring quintiles of about $12-18 \%$ for men and about $11-26 \%$ for women. In some cases, mobility rates of women beyond neighboring quintiles may even reach about 10\%. Overall, the numbers in Table 1 highlight the importance of considering earnings dynamics when modeling future earnings of university graduates.

[Table 1 about here]

Table 2 contains the labor force transition rates from full-time employment at time $t=1$ (i.e., 2001) to four possible employment states (full-time employment, part-time employment, unemployment, not in the labor force) in subsequent years (2002-2011). The numbers in Table 2, which are based on a sample of 22-55 year old university graduates, indicate that full-time employment among men is highly persistent and less persistent among women. Specifically, more than $93 \%$ of the full-time employed men observed in 2001 are full-time employed in 2011. Most men who do not remain full-time employed move to part-time employment, around $1 \%$ transition to unemployment, while about $2 \%$ drop out of the labor force. In contrast, only $53 \%$ of the full-time employed women observed in 2001 are still full-time employed in 2011. However, about $35 \%$ of women transition to part-time employment over this period, less than $1 \%$ move to unemployment, and about $12 \%$ drop out of the labor force. In our empirical analysis we pay particular attention to the role of labor force transitions when modeling earnings dynamics. Due to the differences in labor force dynamics between men and women, we calculate separate debt repayments for male and female university graduates.

\section{[Table 2 about here]}

In our empirical analysis, we study the impact of ignoring earnings mobility by estimating a static earnings model with fixed employment states. This involves assuming that all variation in earnings observed between individuals at time $t$ is permanent 
and persists in the future. To provide an intuition for the use of a static earnings model with fixed employment states, we consider the percentiles for a given population of 22-55 year old university graduates, which is based on a separate calculation of the percentiles in each year. The percentiles over the period 2001-2011 are presented in Figure 1(a), which provides evidence for a considerable spread in the distribution of real earnings that remains relatively constant over time.

To illustrate the implications and shortcomings of a static earnings model, we compare the percentiles presented in Figure 1(a) to actual earnings of a random sample of 22-55 year old university graduates who report positive earnings. The actual earnings of the random sample depicted in Figure 1(b) may be viewed as representative of the development of actual earnings over time. Figure 1(b) reveals that average real earnings have remained quite stable over the sample period despite relatively high earnings mobility. Overall, the comparison of percentiles to actual earnings further motivates the need to consider the implications of static earnings models as compared with dynamic stochastic earnings models to ICL costs.

[Figure 1 about here]

\section{Empirical Strategy}

To estimate ICL subsidies, debt and repayments must be projected for each debtor. Repayments are contingent on assessable earnings. Earnings modeling requires multiple components: a model of labor force transitions, and a model of earnings conditional on labor force state. In Sections 3.1 and 3.2 we describe the process used to develop earnings and labor force models respectively. We intentionally develop both simple static deterministic and more realistic dynamic stochastic models. In Section 3.3 we describe the process used to simulate labor force state, earnings, and repayments for a hypothetical population of university graduates with HECS debts. 


\subsection{Modeling earnings}

Empirical studies have shown that observed characteristics (such as sex, age, occupation, industry, and length of paid employment) explain a relatively small proportion of variability in earnings (see, e.g., Swan, 2006). Unobserved differences can arise due to temporary variation, through illness, higher duties, bonuses, and overtime, or due to permanent differences, like intellectual ability, drive and determination. Additionally, permanent unobserved shocks to earnings may arise due to job mobility and promotions or demotions (see, e.g., Meghir and Pistaferri, 2004), and other incidents not accommodated by observed transitions in labor force or life states. Together, the temporary and permanent differences and shocks manifest as unobserved variation in earnings between individuals, and over time for the same individuals.

Against this background, we develop three earnings models. The distinguishing feature of the three models is how unobserved variability is treated. First, observed variability is accommodated in all three models through an OLS regression fit of logarithm of earnings against observed graduate characteristics. Log earnings is regressed on sex, age as a cubic, number of years of work experience as a quadratic, employment status (full-time or part-time), marital status and presence of dependent children. ${ }^{4}$ The model can be written as

$$
\log \left(E_{i t}\right)=\beta^{\prime} X_{i t}+\varepsilon_{i t},
$$

where $E_{i t}$ is the earnings for individual $i$ at time $t, \beta$ is a vector of coefficients, $X_{i t}$ is the vector of observed covariates, and $\varepsilon_{i t}$ is the error term. Coefficient estimates and standard errors are given in Table 3.

Earnings for individual $i$ at time $t$ can be simulated most simply from this model

\footnotetext{
${ }^{4}$ Interactions between key covariates were considered and AIC was used for model selection. The nonlinearity in age is allowed for by including a cubic spline with 3 degrees of freedom, and similarly a spline with 2 degrees of freedom is included for experience. Cubic splines are flexible alternatives to including quadratic, cubic or higher-dimensional terms in a polynomial model. Prediction from the regression model requires evaluating the spline basis at the values of interest. This cannot be performed manually by using the coefficients in Table 3, but requires evaluation through prediction algorithms. The statistical package ' $\mathrm{R}$ ' was used in all of the modeling and prediction undertaken.
} 
by taking the expected value of earnings corresponding with the covariates for individual $i$ at time $t$. In this instance, unobserved differences between individuals, or within individual earnings over time due to temporary and permanent variation, are assumed to be non-existent.

\section{[Table 3 about here]}

Notably, the explanatory power of the observed covariates is relatively low, producing an R-squared of 0.31 . The question of interest is how to incorporate unobserved earnings variability for the purpose of simulation. A simplified approach is to simulate unobserved earnings variation by assuming that the residuals from (1) are independent and normally distributed with constant variance. ${ }^{5}$ That is, the possibility of serial correlation in unobserved components of earnings is ignored, and all unobserved variation is assumed to be temporary. For the purpose of the simulations herein, we denote this as model 'E1':

$$
\log \left(\widetilde{E}_{i t}\right)=\widehat{\beta}^{\prime} X_{i t}+\nu_{i t}, \quad \text { where } \nu_{i t} \sim N\left(0, \sigma_{\nu}^{2}\right)
$$

$\widetilde{E}_{i t}$ denotes the simulated earnings for individual $i$ at time $t$, and $\nu_{i t}$ represents a normally distributed transitory shock.

An equally naïve approach is to assume that all unobserved variation is a consequence of permanent differences between individuals, and there is no unobserved transitory variability. In this case, the residual from (1) for the $i^{\text {th }}$ individual is assumed to represent a permanent effect, and simulations are constructed by adding this constant permanent component for the $i^{\text {th }}$ individual to the fitted log earnings for all future periods. Under this approach, unobserved differences persist (i.e., the serial correlation in unobserved earnings is unity), resulting in projections similar to those displayed in Figure 1(a). We denote this as model 'E2':

$$
\log \left(\widetilde{E}_{i t}\right)=\widehat{\beta}^{\prime} X_{i t}+u_{i t}, \quad \text { where } u_{i t}=u_{i, t_{0}}=\log \left(E_{i, t_{0}}\right)-\widehat{\beta}^{\prime} X_{i, t_{0}},
$$

\footnotetext{
${ }^{5}$ The residual variance was estimated from the OLS fit as 0.48 .
} 
and $u_{i, t_{0}}$ represents unobserved differences in earnings at time $t_{0}$ due to permanent factors such as IQ, ambition, occupation and industry, among others. ${ }^{6}$

The multiple layers of variability in earnings described at the start of this section lend themselves to modeling through variance component models. Starting with Lillard and Willis (1978) and MaCurdy (1982), variance component models applied to dynamic earnings have been used by econometricians over the past 30 years, and have grown in complexity as panel data has expanded in duration. Following the approach outlined in Higgins (2011), we decompose the residuals from (1) into a permanent and transitory component and further model the permanent component as a random walk thereby allowing for permanent shocks (for graduates remaining in full-time employment): ${ }^{7}$

$$
\log \left(\widetilde{E}_{i t}\right)=\widehat{\beta}^{\prime} X_{i t}+u_{i t}+\nu_{i t}, \quad \text { where } u_{i t+1}=u_{i, t}+w_{i t},
$$

and $w_{i t}$ represents a random permanent shock. $\nu_{i t} \sim N\left(0, \sigma_{\nu}^{2}\right)$ and $w_{i t} \sim N\left(0, \sigma_{w}^{2}\right)$ are assumed to be independent. We denote this model as 'E3'. The model fitting and parameter estimation process used for Model E3 is described in Higgins (2011). ${ }^{8}$ Separate parameters are estimated for males and females, and for earnings shocks

\footnotetext{
${ }^{6}$ For the purpose of the simulations conducted for this paper, $u_{i, t_{0}}$ was estimated from the residuals at 2001 (i.e., $t_{0}=2001$ ).

${ }^{7}$ While the term 'permanent' is used for consistency with the earnings literature, it is assumed to vary over time and can thus be considered a non-mean reverting effect as opposed to a strictly permanent effect (e.g., Dickens, 2000). Using a random walk for the permanent component can be justified through observation of the residual variances and covariances from (1). Specifically, increasing variance and long lagged autocovariances with age may be captured through a random walk. A random shock to the permanent component allows for changes to unobserved factors such as occupation and industry of employment, but also allows for different rates of earnings growth among individuals which have a persistent effect on earnings.

${ }^{8}$ The approach used for variance decomposition and parameter estimation is similar to Higgins (2011), who models hourly wages for the general population. For completion, the parameter estimates for Model E3 are as follows: for graduates remaining in full-time earnings between year $t$ and $t+1, \sigma_{w}^{2}=$ 0.005 and 0.015 , and $\sigma_{\nu}^{2}=0.17$ and 0.08 , for males and females respectively. For both sexes remaining in part-time earnings, a random walk for the permanent component was not justified empirically (that is, $\left.\sigma_{w}^{2}=0\right)$ and the variance of the transitory shock $\sigma_{\nu}^{2}=0.45$. Similarly, for both sexes transitioning between full-time and part-time status, $\sigma_{w}^{2}=0$ and $\sigma_{\nu}^{2}=0.30$. In addition to the variance components, when simulating one also needs a starting value for the permanent component for each individual. Unbiased estimates of the starting value for the permanent component are the residuals of the OLS fit, weighted to ensure that the variance of the simulated earnings from Model E3 equals the variance of actual earnings.
} 
between full-time states, between part-time states, and for cases when individuals transition between labor force states.

Despite the superior realism of Model E3 when compared with E1 and E2, there are certain limitations that are worth describing briefly here. Firstly, while the observed earnings shocks show evidence of kurtosis, we assume normally distributed variance components. Secondly, there is evidence that the variance components differ with respect to age, however, we have assumed they are constant with respect to age for Model E3. Thirdly, it is assumed that Model E3 holds for all graduates, and that the estimates for $\sigma_{\nu}^{2}$ and $\sigma_{w}^{2}$ are the same across all individuals with the same labour force state. While a random walk for earnings is supported in the literature, there is also empirical evidence for 'profile heterogeneity', such that individuals follow personspecific earnings profiles (see, e.g., Baker, 1997). Browning et al. (2010) have argued that both processes should be accommodated in earnings models. This is a clear extension of Model E3, and will be considered in future work.

\subsection{Modeling labor force state}

Predicting an individual's future labor force state is a necessary step prior to predicting future earnings. For the ICL simulations performed, three labor force models were considered. The first, denoted 'L1', simply assumes that the observed labor force state for individual $i$ in 2001 continues to apply until the end of the simulation period. That is, labor force state remains static.

The second model, denoted 'L2', assumes that the observed labor states for individual $i$ from 2001 to 2011 hold, and that the state as at 2011 continues to apply until the end of the simulation period. In this case, labor state for individual $i$ is fixed from 2012 onwards.

A limitation of these models is that actual labour force states are only available up to 2011. The third model, denoted 'L3', is developed to overcome this limitation through the estimation of transition probabilities between labour force states. While labour force state can be modeled as discrete multinomial choices, the use of the multinomial 
logistic assumes independent odds ratios across the discrete choice categories (Greene, 2012). We adopt a more flexible approach which involves three nested bivariate logistic sub-models. The first sub-model (L3.a) determines whether an individual is employed or not employed. Conditional on being employed, the second (L3.b) determines whether an employed individual works full-time or part-time. Conditional on the first choice being not employed, the third sub-model (L3.c) determines whether the individual is unemployed or not in the labour force (the acronym NILF is used to denote this latter labour force state). If we let $Y_{i t}$ be a random variable indicating the bivariate choice, $\beta$ is a vector of coefficients, $X$ is a vector of observed covariates, and if we use a superscript to identify each logistic sub-model, then:

$$
\begin{gathered}
P\left(Y_{i t}^{a}=k \mid X_{i t}^{a}\right)=\frac{\exp \left(\beta_{k}^{a^{\prime}} X_{i t}^{a}\right)}{1+\exp \left(\beta_{k}^{a^{\prime}} X_{i t}^{a}\right)} \text { for } k=0 \text { (not employed), } 1 \text { (employed) } \\
P\left(Y_{i t}^{b}=k \mid X_{i t}^{b}, Y_{i t}^{a}=1\right)=\frac{\exp \left(\beta_{k}^{b^{\prime}} X_{i t}^{b}\right)}{1+\exp \left(\beta_{k}^{b^{\prime}} X_{i t}^{b}\right)} \text { for } k=0 \text { (part-time), } 1 \text { (full-time) } \\
P\left(Y_{i t}^{c}=k \mid X_{i t}^{c}, Y_{i t}^{a}=0\right)=\frac{\exp \left(\beta_{k}^{c^{\prime}} X_{i t}^{c}\right)}{1+\exp \left(\beta_{k}^{c^{\prime}} X_{i t}^{c}\right)} \text { for } k=0 \text { (NILF), } 1 \text { (unemployed) }
\end{gathered}
$$

Covariates considered in L3 are sex, a cubic spline in age, marital status, and flags to indicate presence of dependent children. Sex was interacted with each of these covariates. ${ }^{9}$ As the probability of labor force transitions is dependent on past labor states, state dependencies are incorporated by including one- and two-step lagged labor force state as covariates in each of the three nested sub-models. ${ }^{10}$ Coefficient estimates and standard errors are given in Table $4 .^{11}$

\footnotetext{
${ }^{9}$ While other variables feature within the microsimulation and econometric literature (e.g., occupation, industry, disability, earnings, partner's earnings), these are omitted and assumed to be part of the error structure.

${ }^{10} \mathrm{An}$ interpretation of including lagged labor force state is that the act of being in a particular current state alters the individual's preferences and constraints for being in a particular future state. This is known as true state dependence in the dynamic panel literature (Hsiao, 2003). An alternative interpretation, known as spurious state dependence, is that the individual's preferences and constraints are not influenced by the experience of being in a particular state, but rather unobserved individual effects are responsible for apparent labor force state persistence over time. An extension of this research would be to consider the predictive power of this alternative specification as compared to including lagged labor force state in our logistic models.

${ }^{11} \mathrm{~A}$ limitation when generating labor force transition rates from HILDA is that the data reflect the specific economic circumstances (e.g., strong economic growth for the majority of the period), and
} 


\subsection{Simulating Income Contingent Loan Repayments}

The simulation process involves estimating ICL debt and repayments over a 30 year projection period for a subpopulation of university graduates. The subpopulation selected is male and female university graduates aged between 20 and 35 from the HILDA sample who were either full-time or part-time employed in 2001. ${ }^{12}$ A microsimulation model is built to undertake the simulations. Microsimulation in this context involves simulating the labor force state, earnings, repayments and debt for each individual ICL debtor. Monte Carlo simulation was used to project earnings and labor force state for those models that included stochastic components.

The following steps are undertaken for each individual $i$ :

1. Labour force state is simulated for years 2002 to 2030 using one of the three labor force models described in Section 3.2.

2. The annual earnings are then simulated using the earnings models in Section 3.1. Conditional on simulated labour force state being either full-time or part-time, earnings are simulated for each year $t$ (where $t$ ranges from 2002 to 2030), otherwise, if labor force state is unemployed or NILF, then earnings are set to zero.

3. The projected earnings for 2002 to 2030 are then input into the microsimulation model. ICL compulsory repayments are calculated by determining the income threshold and repayment rate corresponding with the simulated earnings, and applying this rate to the earnings. Outstanding debt in each year is calculated by indexing debt at time $t$ and then deducting new compulsory repayments.

Because models E1, E3 and L3 have stochastic components, repeating the above steps for the same individual may yield a different set of simulated labor force states and earnings. In order to control for the variability inherent in Monte Carlo simulation,

projections based on this information will presume a continuation of these conditions. While future projections must allow for expected trends in participation rates, it should be noted that the model presented here is based exclusively on historic data.

${ }^{12}$ This is a subpopulation of 336 individuals, 189 of whom are female and 147 male. 
the steps above are repeated 500 times for each individual in the subpopulation. ${ }^{13}$ The average outstanding debt and average repayment is then output for the subpopulation at each time period.

As described in Section 1, the costs of an ICL associated with delayed or nonrepayment of debt can be expressed as a subsidy. This can be expressed mathematically as:

$$
\frac{\mathrm{PV}(\text { outlays })-\mathrm{PV}(\text { repayments })}{\mathrm{PV}(\text { outlays })},
$$

where PV is the present value. The present value of the outlays is simply the initial debt, and the present value of repayments is the discounted value of all future repayments made. Clearly, if an individual's income falls below the minimum repayment threshold in each future year, the subsidy would be $100 \%$. Conversely, if the present value of repayments equals the initial loan amount, the subsidy would be 0\%. Subsidies are calculated using a discount rate of $5.5 \%$, which as stated in Section 1, is the approximate long-term government cost of borrowing. Subsidies are calculated for the various labor force and earnings model combinations, for males and females combined and separately.

\section{Results}

\subsection{Predicted Earnings}

The earnings and labor force models used in the simulations are summarized in Table 5.

[Table 5 about here]

Prior to presenting the implications of the different models to ICL debt, we present a sample of actual earnings for the period 2001-2011 and predicted earnings for the period 2012-2030 for each of the three earnings models. The labor force Model L3 is used for

\footnotetext{
${ }^{13}$ For the subpopulation considered this implies that labor force state and annual earnings are simulated approximately 5 million times for each combination of earnings and labor force model.
} 
the 2012-2030 projection period. Figure 2 reveals that predicted earnings obtained from Model E1, in which all unobserved variation is assumed to be temporary, are extremely volatile and in some cases lead to much greater variability than the variation than the actual levels observed over the period 2001-2011. As a consequence, the predicted earnings pattern of Model E1 does not resemble the actual earnings pattern, reinforcing that earnings prediction requires incorporation of permanent variation in addition to temporary.

[Figure 2 about here]

In contrast to Model E1, the predicted earnings obtained from Model E2, which assumes that all unobserved variation is permanent, are persistent over the period 20122030. Although the levels of the predicted earnings of Model E2 overlap with the range of actual earnings observed from 2001-2011, Model E2 does not capture important shocks to earnings (both temporary and permanent). Taken together, Models E1 and E2 reveal the shortcomings of predicting earnings by relying on only temporary or permanent variation.

When studying predicted earnings obtained from a model that accounts for both temporary and permanent unobserved variation, and permanent shocks, we find that the combined examination of these shocks allows for more realistic levels of earnings persistency and variation. Model E3, which takes into account the different sources of unobserved variation, produces a predicted earnings pattern that broadly resembles the actual earnings pattern observed in 2001-2011. Model E3 is favored on theoretical as well as empirical grounds over Models E1 and E2.

\subsection{Debt Repayments}

To gain a better understanding of the implications of static and dynamic earnings modeling, we use the earnings predictions, a sample of which is presented in Figure 2, to calculate the remaining average debt of 2001 graduates over the period 2002-2030, using different assumptions about the projection of labor force states. The simulation 
process followed is detailed in Section 3.3.

We assume that the debt of our subpopulation at the start of the simulation period is $\$ 25,000$ (in 2011 dollars), which is consistent with an average HECS debt of a 4year degree for a student completing study in 2011. We further employ the 20102011 income thresholds and repayment rates of HECS and assume a CPI of $2.5 \%$ and earnings growth of $4 \%$ per annum beyond 2011. ${ }^{14}$

To study the economic implications of differing labor force dynamics, we simulate average outstanding debt with earnings estimated using our preferred earnings model, Model E3, under the three labor force Models L1, L2, and L3. The actual and predicted average outstanding debts are presented in Figure $3 .^{15}$ We observe that Model L1 overestimates the actual outstanding debt during the period 2001-2011 and remains at a relatively high level during the projection period 2012-2030. In contrast, Model L2, which is based on the actual labor force state over the period 2001-2011 and assumes that the labor force state in 2011 applies for the entire projection period, is very close to the actual outstanding debt. This closeness implies that the earnings predicted by Model E3 generate a similar pattern of compulsory payments as actual earnings, giving credibility to the model structure of E3. As expected, for Model L2, due to the assumption that the labor force state observed in 2011 persists for the projection period, the average outstanding debt remains at a relatively high level after 2011.

[Figure 3 about here]

Model L3 produces debt estimates that are consistent with those based on actual earnings, which is support for the predictive accuracy of this model in this context. Incorporating the chance of transition to other labor force states leads to lower average debt in the long run compared to Model L2. While labor force mobility may result in periods of greater or lesser (or nil) repayment as ICL thresholds are crossed, our findings suggest that, on balance, modeling realistic patterns of labor force mobility

\footnotetext{
${ }^{14}$ Our calculations of the remaining average debt take into account the underlying income thresholds and repayment rates of HECS, which are as follows: $\$ 44,912: 4 \%, \$ 50,028: 4.5 \%, \$ 55,143: 5.0 \%$, $\$ 58,041: 5.5 \%, \$ 62,390: 6.0 \%, \$ 67,570: 6.5 \%, \$ 71,126: 7.0 \%, \$ 78,273: 7.5 \%, \$ 83,407: 8.0 \%$.

${ }^{15}$ For Figures 3, 4, 5 and 6, the average outstanding debt figures are given in 2011 dollars.
} 
yields faster repayments and lower long run debt under HECS scheme rules than under static labor states.

Figure 4 illustrates the implications of using earnings Models E1-E3 in combination with labor force Model L3. We find that the average outstanding debt predicted by earnings Model E1 is lower than the actual outstanding debt observed from 2001-2011. Moreover, Model E1 predicts that the average outstanding debt is close to zero at the end of the projection period in 2030. Since Model E1 assumes that all unobserved variation is temporary, it introduces considerable yearly variation in earnings. While the volatility implies that an individual has an increased likelihood of falling below the minimum income threshold, it also permits a greater proportion of university graduates with opportunities to exceed the minimum threshold. The consequence is that predicted average outstanding debt in the presence of this earnings volatility declines much faster than the actual debt.

[Figure 4 about here]

In contrast to Model E1, average outstanding debt levels predicted by Model E2, which assumes that all unobserved variation is permanent, are much higher than actual outstanding debt levels. Since predicted earnings of university graduates under Model E2 are highly persistent, those graduates under the minimum threshold are very unlikely to cross the threshold. As a result, outstanding debt levels predicted by Model E2 are much higher than actual outstanding debt levels.

Our preferred model, Model E3, takes into account temporary and permanent shocks and produces more realistic levels of earnings persistency and variation than Models E1 and E2, resulting in more credible average outstanding debt estimates. We find that the average outstanding debt predicted by Model E3 is very close to the actual average outstanding debt over the period 2001-2011. Moreover, we observe a persistent decline in the average outstanding debt predicted by Model E3 over the projection period 2012-2030 (which is partly a consequence of the labor force transitions from Model L3). 
Since our descriptive analysis of earnings and labor force mobility reveals considerable differences between male and female university graduates (Tables 1 and 2), we are interested in studying the extent to which our choice of earnings model affects predicted average outstanding debts of male and female university graduates. Figures 5 and 6 present actual and predicted average outstanding debt levels of male and female university graduates obtained from our three earnings models in combination with our preferred labor force model (L3).

[Figure 5 about here]

[Figure 6 about here]

The figures reveal substantial differences in both actual and predicted average outstanding debt levels between male and female university graduates. While actual average debt levels of male graduates drop below $\$ 3,000$ in 2011, average debt levels of female graduates remain above $\$ 10,000$. Moreover, predicted average outstanding debt levels of male university graduates are either close to zero (Models E1 and E3) or very low (Model E2) at the end of the projection period. In contrast, predicted average outstanding debt levels of female university graduates remain relatively high at the end of the projection period, with exemption of the prediction obtained from Model E1, which assumes that earnings are extremely volatile. Overall, our findings reveal considerable differences in the repayment capacity of male and female university graduates.

\subsection{Implications for Subsidy Calculations}

Our findings suggest that the results obtained from static and dynamic models are quite different and have important implications for ICL design. To illustrate the differences, we calculate the subsidy costs based on alternative model predictions. Table 6 includes the predicted subsidy costs in percentage terms obtained from the earnings and labor force models described in Section $3 .{ }^{16}$ When comparing labor force models in

\footnotetext{
${ }^{16}$ Importantly, the subsidy estimates for model E3-L3 presented here should not be seen as exact measures of the interest and debt non-repayment subsidies of new HECS debtors for a number of
} 
combination with our preferred specification of earnings (Model E3) for the sample of male and female university graduates, we find that the underlying subsidies predicted by labor force Model L1 are considerably higher (26\%) than the subsidies obtained from Model L2 (21\%), which are only slightly higher than the subsidies estimated by our preferred labor force Model L3 (20\%).

[Table 6 about here]

To appreciate the implication of the $6 \%$ subsidy difference between Models L1 and L3, we consider the magnitude in dollar terms. Using a figure of $\$ 3.8$ billion of new loans per annum for the Australian Higher Education Loan Program (HELP) (Norton, 2013), this corresponds with a difference between Models L1 and L3 of over $\$ 220$ million.

When comparing earnings models in combination with our preferred labor force model (Model L3), we observe that the subsidies predicted by Model E1 are considerably lower (13\%) than those of Model E3 (20\%), while the subsidies obtained from Model E2 (27\%) are substantially above those of Model E3. Again, the difference between the preferred model (E3) and the simplistic models are in the order of $\$ 200 \mathrm{~m}$ to $\$ 300 \mathrm{~m}$.

A separate consideration of male and female university graduates indicates that the bulk of difference in predicted costs is attributable to the modeling of female university graduates, confirming the complexity and variability of earnings and labor force dynamics of female graduates as compared with male graduates.

Predicted subsidies obtained from Model E3 for female graduates vary across labor force models from 36\% (Model L1) to 27\% (Model L3). When using our preferred labor force model (Model L3), predicted subsidies of female graduates vary from $17 \%$ (Model E1) to 36\% (Model E2), revealing a considerable spread in predicted subsidies

reasons. Firstly, the subpopulation of debtors in the simulations is constrained to graduates aged 22 to 35, whereas HECS debtors can include non-completers and all age groups. Secondly, the initial debt in the simulations is assumed to be $\$ 25,000$, which represents the cost of a four-year degree, and therefore may be greater than the average actual debt for new completers. Thirdly, the simulations do not incorporate non-repayment due to death or overseas migration. The important result is not the absolute magnitude of the subsidies, but rather the relative difference in subsidy estimates under the different model structures. 
of over $\$ 350 \mathrm{~m}$. In contrast, when applying our preferred labor force model (Model L3) to the sample of male graduates, the variation in subsidies is in the order of $\$ 100 \mathrm{~m}$. Clearly, as the size of the student population grows and as tuition fees (and loans) increase, the economic implications of misestimating future earnings becomes more critical.

\section{Conclusions}

The design of sensible public policy relies on accurate costings which, in many contexts, depend in turn on future income predictions. The importance of accurate models of earnings dynamics has been recognized in the design and assessment of taxation and pension scheme design, however, earnings models in education policy research tend to rely on cross-sectional assumptions (e.g., Chapman and Liu, forthcoming). Since the design of income contingent loans relies directly on future assessable incomes, ignoring relevant aspects of earnings and employment dynamics may have severe implications for the calculation of debt repayments and the underlying costs of an ICL scheme. Against this background, we examine to what extent the complexity and realism of earnings models affect ICL costs, using a sample of university graduates from the Household, Income and Labour Dynamics in Australia (HILDA) Survey. Using Australian data enables us to compare predicted debt repayments to actual repayments under the Australian Higher Education Contribution Scheme (HECS). In our empirical analysis, we compare the results obtained from a static cross-sectional model to those of a dynamic panel model that allows for permanent and transitory shocks.

Our findings reveal that the accuracy of modeling earnings dynamics has important implications for subsidy calculations and the design of income contingent loans. We compare predicted earnings obtained from models in which unobserved variation is either assumed to be temporary or permanent to predictions obtained from a model that accounts for both temporary and permanent variation. We find that predicted earnings are extremely volatile if we ignore permanent unobserved variation, and highly 
persistent if we ignore temporary shocks. Combining temporary and permanent variation (with allowance for permanent shocks) produces more realistic levels of predicted earnings persistency and variation. ${ }^{17}$

We study the implications of considering earnings and labor force dynamics for the prediction of average outstanding debts and find that ignoring dynamic aspects of earnings and labor force transitions may severely bias the prediction of outstanding debts. At the same time, taking into account temporary and permanent variation and shocks produces superior predictions of actual outstanding debt levels. We distinguish between male and female university graduates to show that outstanding debt levels of female graduates remain relatively high until the end of our projection period, revealing considerable differences in the repayment capacity between the two groups. We further illustrate the implications of ignoring dynamic aspects of earnings and labor force modeling for the calculation of subsidies. The magnitude of the difference in the results when dynamic earnings models are used, as compared with traditional crosssectional earnings models, reinforces the importance of considering earnings dynamics in education policy research, and public policy generally.

\footnotetext{
${ }^{17}$ While we believe the range of models used herein are sufficient to convey the key message of this paper, additional models could be presented and compared to further explore the implications of model complexity on ICL costings. Specifically, limitations and possible extensions of Model E3 are briefly described at the end of Section 3.1.
} 


\section{Tables and Figures}

Table 1: Average mobility rates across earnings quintiles between two consecutive waves

\begin{tabular}{lccccc}
\hline & \multicolumn{5}{c}{ Wave $t$ to Wave $t+1$} \\
\cline { 2 - 6 } Quintile & 1st & 2nd & 3rd & 4th & 5th \\
\hline Men, full- and part-time employed & & & & & \\
1st & 72.02 & 15.86 & 5.08 & 2.70 & 4.33 \\
2nd & 12.64 & 65.02 & 16.76 & 3.77 & 1.80 \\
3rd & 4.98 & 14.36 & 61.44 & 17.45 & 1.78 \\
4th & 4.96 & 2.70 & 12.19 & 66.13 & 14.02 \\
5th & 5.65 & 2.28 & 2.11 & 11.77 & 78.20 \\
\hline Women, full-time employed & & & & & \\
1st & 54.64 & 25.99 & 10.28 & 5.22 & 3.87 \\
2nd & 11.16 & 55.71 & 24.50 & 7.43 & 1.19 \\
3rd & 2.99 & 14.02 & 50.48 & 26.09 & 6.42 \\
4th & 2.04 & 4.62 & 19.70 & 57.76 & 15.87 \\
5th & 2.12 & 0.88 & 2.54 & 14.74 & 79.71 \\
\hline Women, part-time employed & & & & & \\
1st & 57.60 & 26.18 & 9.54 & 3.34 & 3.34 \\
2nd & 12.05 & 52.76 & 23.20 & 9.56 & 2.43 \\
3rd & 3.96 & 17.38 & 50.88 & 22.26 & 5.53 \\
4th & 3.66 & 6.67 & 16.69 & 56.24 & 16.75 \\
5th & 2.88 & 2.49 & 8.64 & 20.39 & 65.59 \\
\hline
\end{tabular}


Table 2: Full-time employed at time $t=1$. Labor force distribution in subsequent years

\begin{tabular}{lcccc}
\hline Year & Full-time & Part-time & Unemployed & NILF \\
\hline Men & & & & \\
2 & 96.02 & 1.99 & 1.28 & 0.71 \\
3 & 93.31 & 4.40 & 0.98 & 1.31 \\
4 & 92.38 & 4.90 & 0.73 & 2.00 \\
5 & 91.26 & 5.24 & 1.17 & 2.33 \\
6 & 91.34 & 6.19 & 0.41 & 2.06 \\
7 & 92.68 & 3.77 & 0.89 & 2.66 \\
8 & 93.99 & 3.85 & 0.24 & 1.92 \\
9 & 92.78 & 3.87 & 1.29 & 2.06 \\
10 & 94.40 & 2.52 & 1.12 & 1.96 \\
11 & 93.53 & 3.24 & 1.18 & 2.06 \\
\hline Women & & & & \\
2 & 85.77 & 10.63 & 0.76 & 2.85 \\
3 & 79.70 & 14.80 & 0.42 & 5.07 \\
4 & 75.29 & 17.85 & 0.00 & 6.86 \\
5 & 71.81 & 21.57 & 0.49 & 6.13 \\
6 & 68.57 & 21.82 & 1.04 & 8.57 \\
7 & 69.67 & 19.95 & 1.37 & 9.02 \\
8 & 65.61 & 23.41 & 0.87 & 10.12 \\
9 & 61.52 & 26.97 & 0.61 & 10.91 \\
10 & 59.22 & 28.80 & 0.65 & 11.33 \\
11 & 53.12 & 34.72 & 0.35 & 11.81 \\
\hline
\end{tabular}


Figure 1: Percentiles and actual earnings
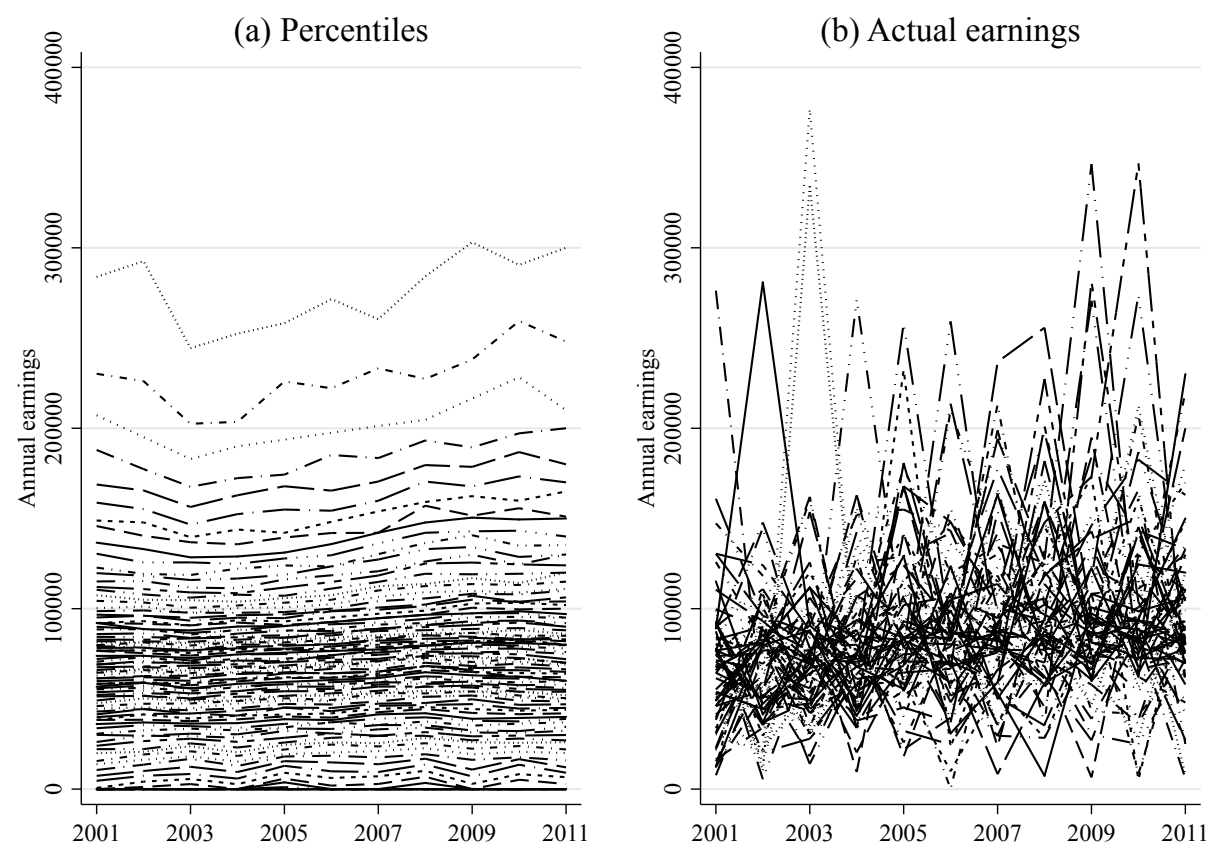
Table 3: Coefficient estimates for OLS fit to log earnings

\begin{tabular}{lcc}
\hline & Coef. & $\mathrm{SE}$ \\
\hline Intercept & $10.770^{* * *}$ & 0.052 \\
Employment status $($ part-time $)$ & $-1.164^{* * *}$ & 0.160 \\
Age $(\mathrm{df}=1)$ & -0.089 & 0.086 \\
Age $(\mathrm{df}=2)$ & 0.224 & 0.191 \\
Age $(\mathrm{df}=3)$ & $-0.298^{* *}$ & 0.100 \\
Married & $0.109^{* * *}$ & 0.025 \\
Dependent child present & $0.057^{*}$ & 0.024 \\
Experience $(\mathrm{df}=1)$ & $0.977^{* * *}$ & 0.177 \\
Experience $(\mathrm{df}=2)$ & $0.420^{* * *}$ & 0.112 \\
Female $\times$ Age $(\mathrm{df}=1)$ & $-0.280^{*}$ & 0.115 \\
Female $\times$ Age $(\mathrm{df}=2)$ & $-0.580^{*}$ & 0.256 \\
Female $\times$ Age $(\mathrm{df}=3)$ & 0.026 & 0.137 \\
Female $\times$ Married & $-0.120^{* * *}$ & 0.033 \\
Female $\times$ Dependent child present & $-0.176^{* * *}$ & 0.045 \\
Part-time employed $\times$ Age $(\mathrm{df}=1)$ & $-1.085^{* * *}$ & 0.241 \\
Part-time employed $\times$ Age $(\mathrm{df}=2)$ & $-3.016^{* * *}$ & 0.540 \\
Part-time employed $\times$ Age $(\mathrm{df}=3)$ & $-2.191^{* * *}$ & 0.272 \\
Part-time employed $\times$ Married & $0.259^{* * *}$ & 0.077 \\
Part-time employed $\times$ Experience $(\mathrm{df}=1)$ & $3.199^{* * *}$ & 0.475 \\
Part-time employed $\times$ Experience $(\mathrm{df}=2)$ & $2.066^{* * *}$ & 0.306 \\
Female $\times$ Part-time employed $\times$ Age $(\mathrm{df}=1)$ & $0.640^{*}$ & 0.268 \\
Female $\times$ Part-time employed $\times$ Age $(\mathrm{df}=2)$ & $1.862^{* *}$ & 0.604 \\
Female $\times$ Part-time employed $\times$ Age $(\mathrm{df}=3)$ & $1.475^{* * *}$ & 0.303 \\
Female $\times$ Part-time employed $\times$ Married & $-0.321^{* * *}$ & 0.086 \\
Female $\times$ Part-time employed $\times$ Experience $(\mathrm{df}=1)$ & $-1.367^{*}$ & 0.531 \\
Female $\times$ Part-time employed $\times$ Experience $(\mathrm{df}=2)$ & $-1.749^{* * *}$ & 0.348 \\
\hline & & \\
\hline
\end{tabular}

*** Significant at the $0.1 \%$ level; ** Significant at the $1 \%$ level; * Significant at the $5 \%$ level. 


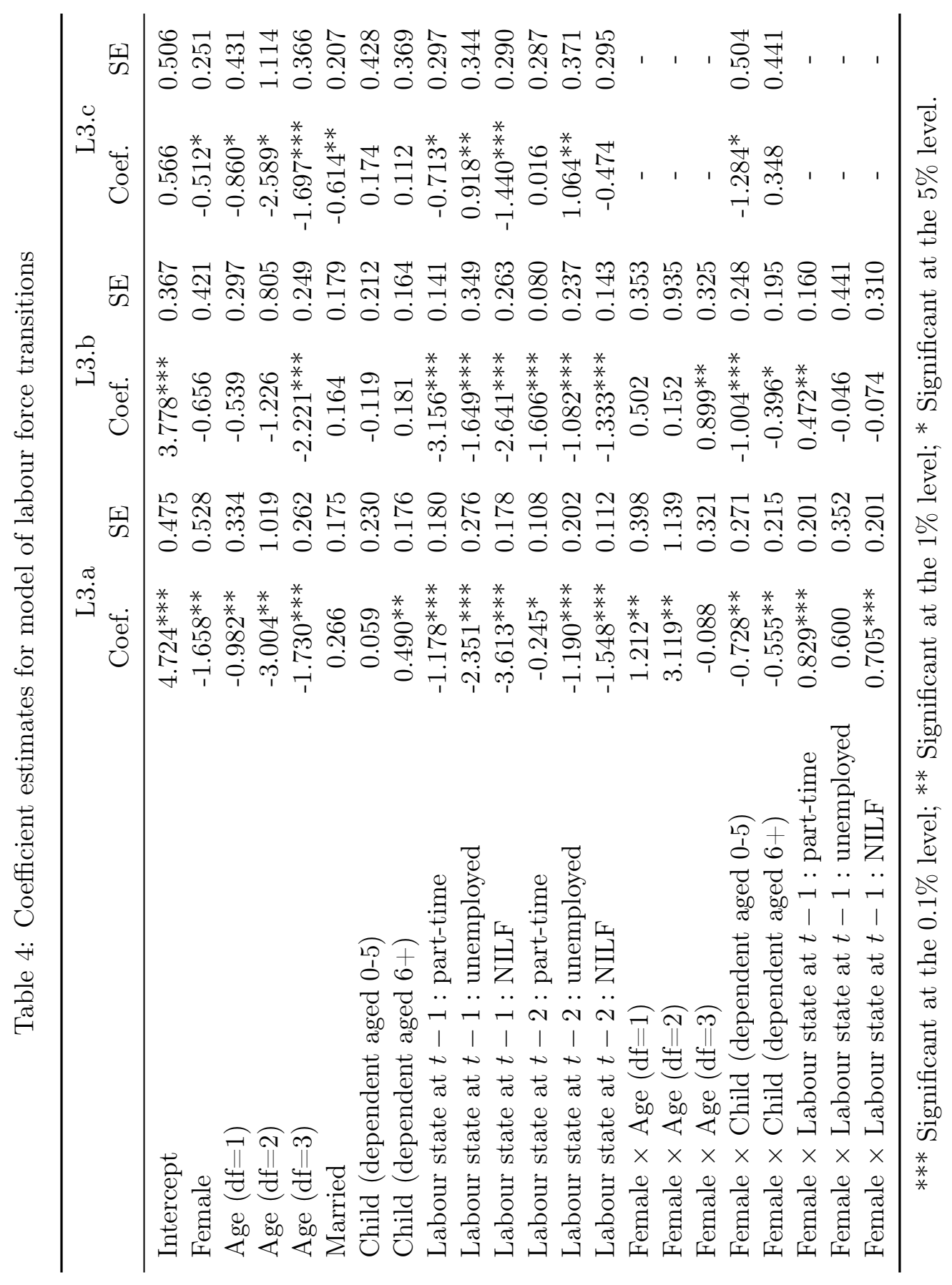


Table 5: Earnings and labour force models used in the simulation

\begin{tabular}{ll}
\hline Model & Description \\
\hline E1 & $\begin{array}{l}\text { Observed earnings variation through OLS fit. All unobserved variation is assumed } \\
\text { to be temporary; no unobserved permanent variation. } \\
\text { E2 }\end{array}$ \\
& $\begin{array}{l}\text { Observed earnings variation through OLS fit. All unobserved variation is assumed } \\
\text { to be permanent; no allowance for temporary variation, nor for permanent shocks. }\end{array}$ \\
E3 & $\begin{array}{l}\text { Observed earnings variation through OLS fit. Unobserved variation is represented } \\
\text { through a temporary and permanent component, and shocks to the permanent } \\
\text { component are accommodated through a random walk (for graduates remaining in } \\
\text { full-time employment). }\end{array}$ \\
L1 & $\begin{array}{l}\text { Actual labour force state as at 2001 applies for 2002- 2030. } \\
\text { Actual labour force states for 2001-2011 applies over this period. Actual labour }\end{array}$ \\
force state in 2011 applies for 2012-2030. & Labour force projections for 2002 until 2030 are based on three nested bivariate \\
& logistic models that include one-step and two-step lagged labour states as covariates. \\
\hline
\end{tabular}

Figure 2: Predicted earnings
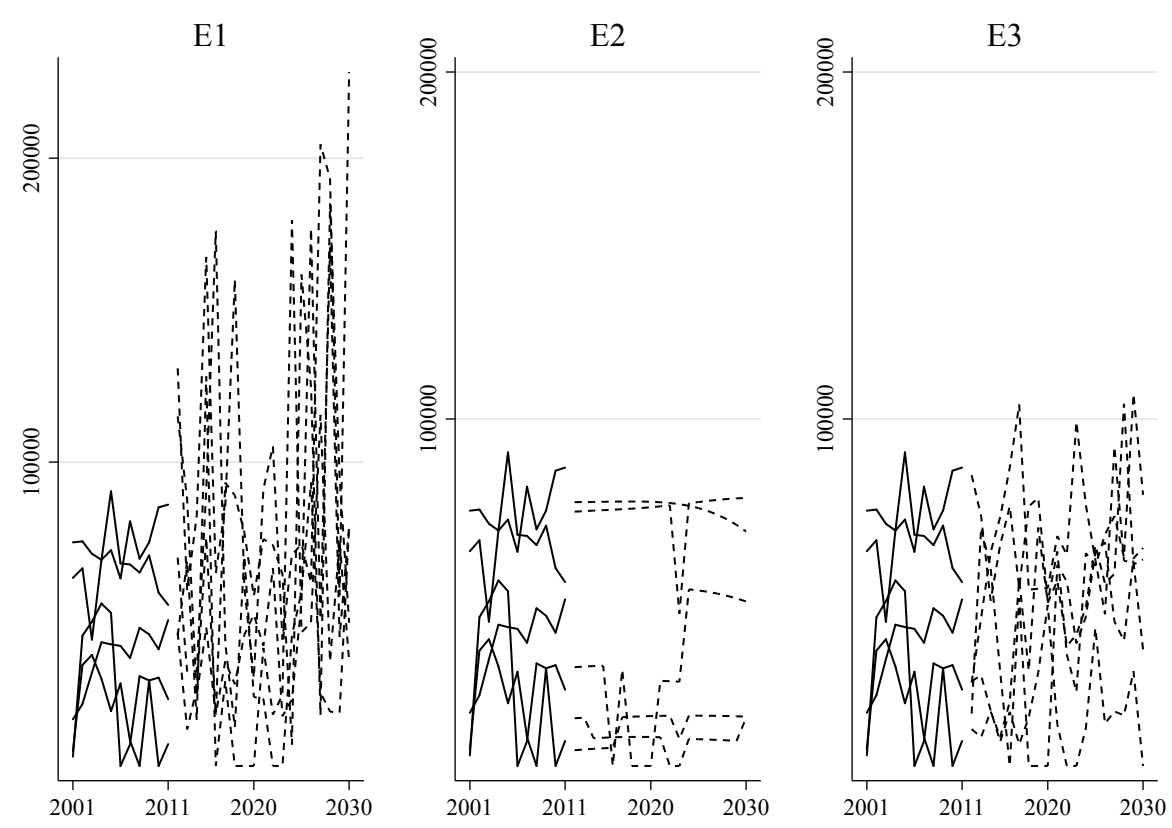
Figure 3: Male and female university graduates, Model E3

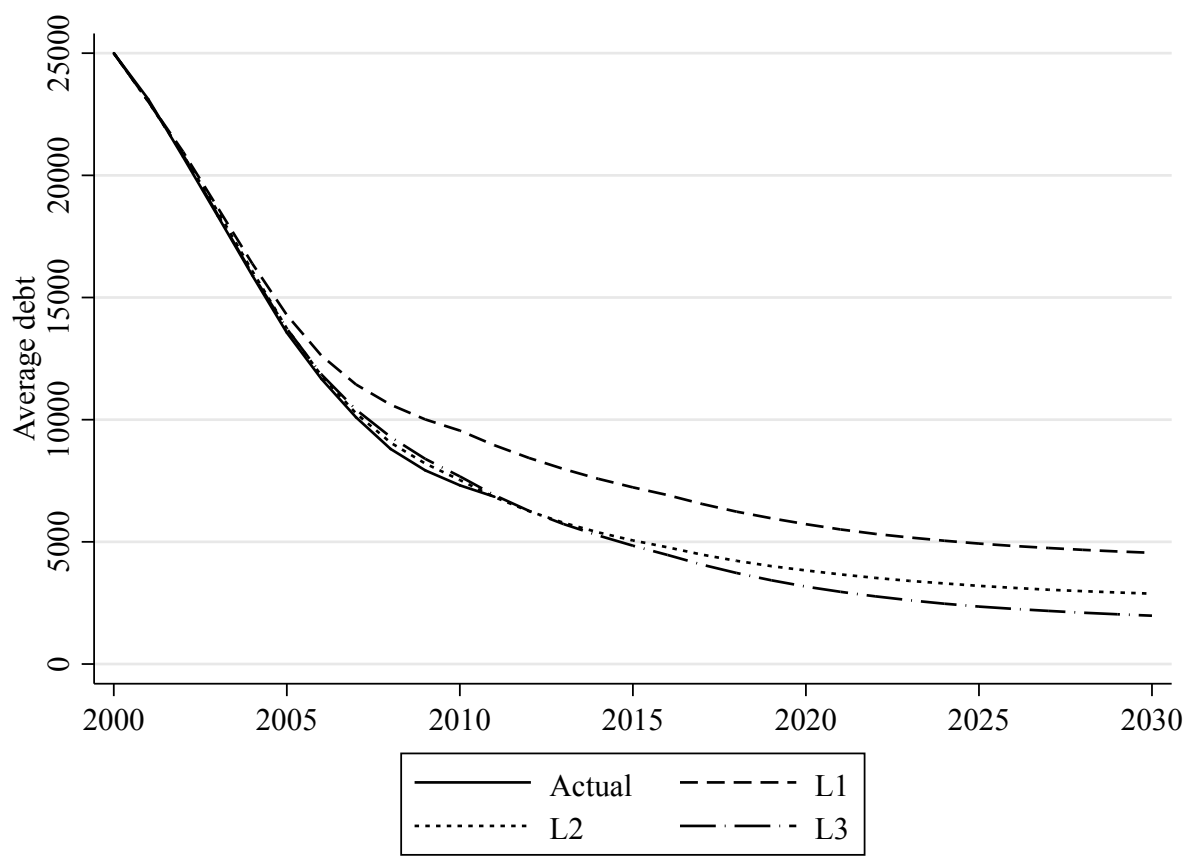

Figure 4: Male and female university graduates, Model L3

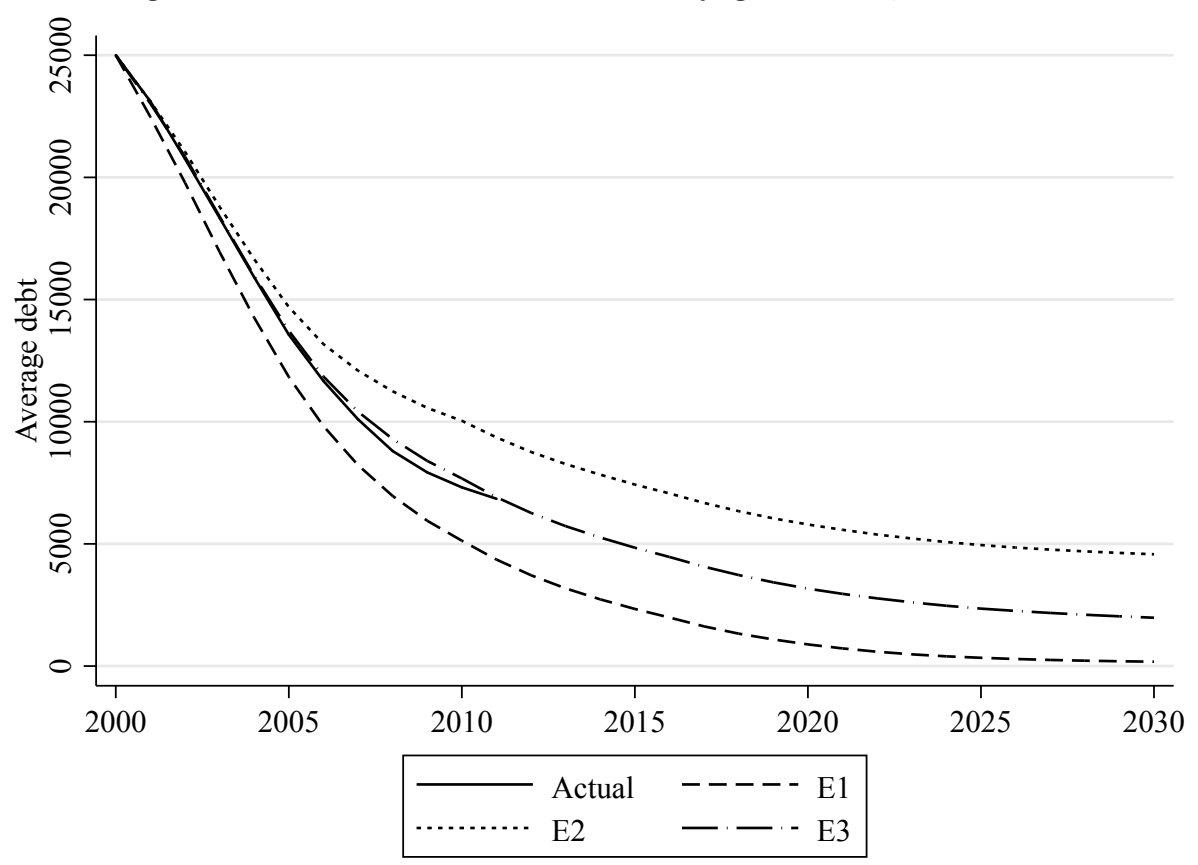


Figure 5: Male university graduates, Model L3

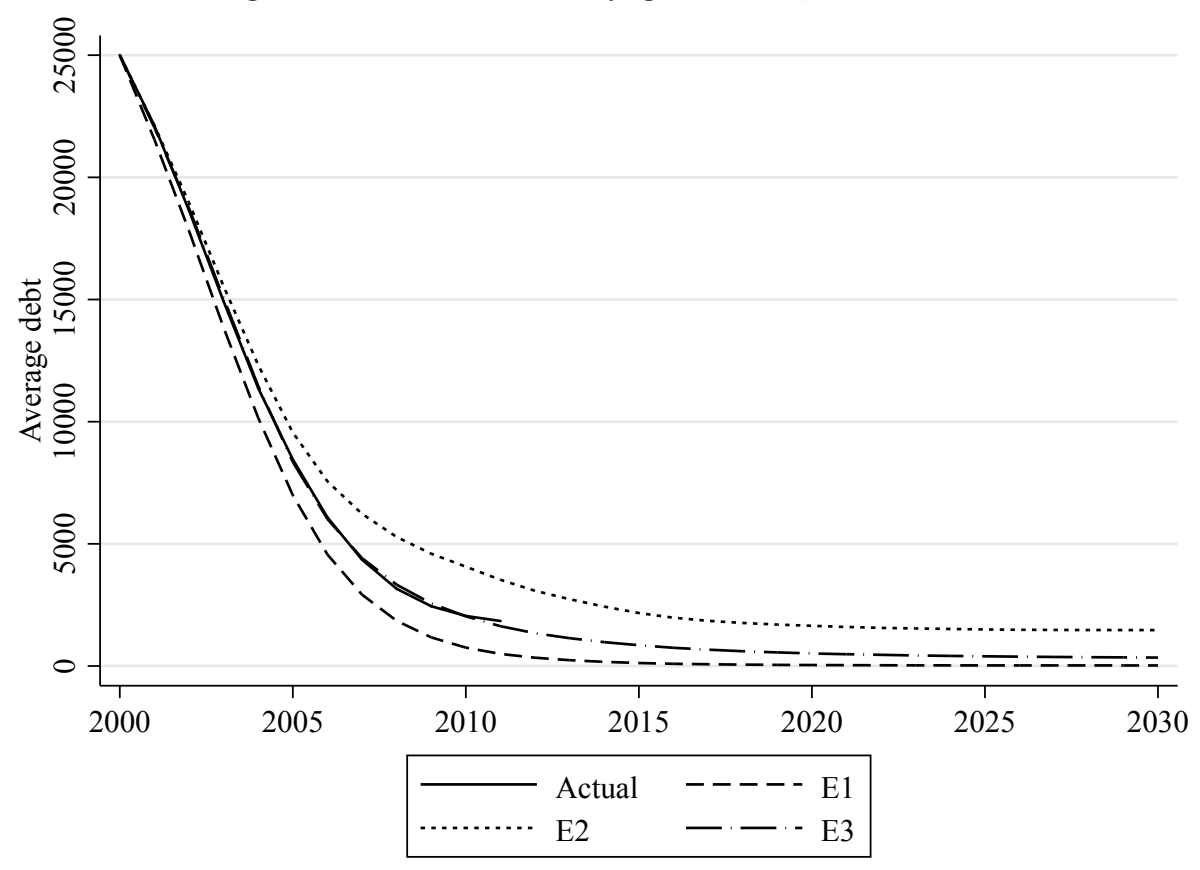

Figure 6: Female university graduates, Model L3

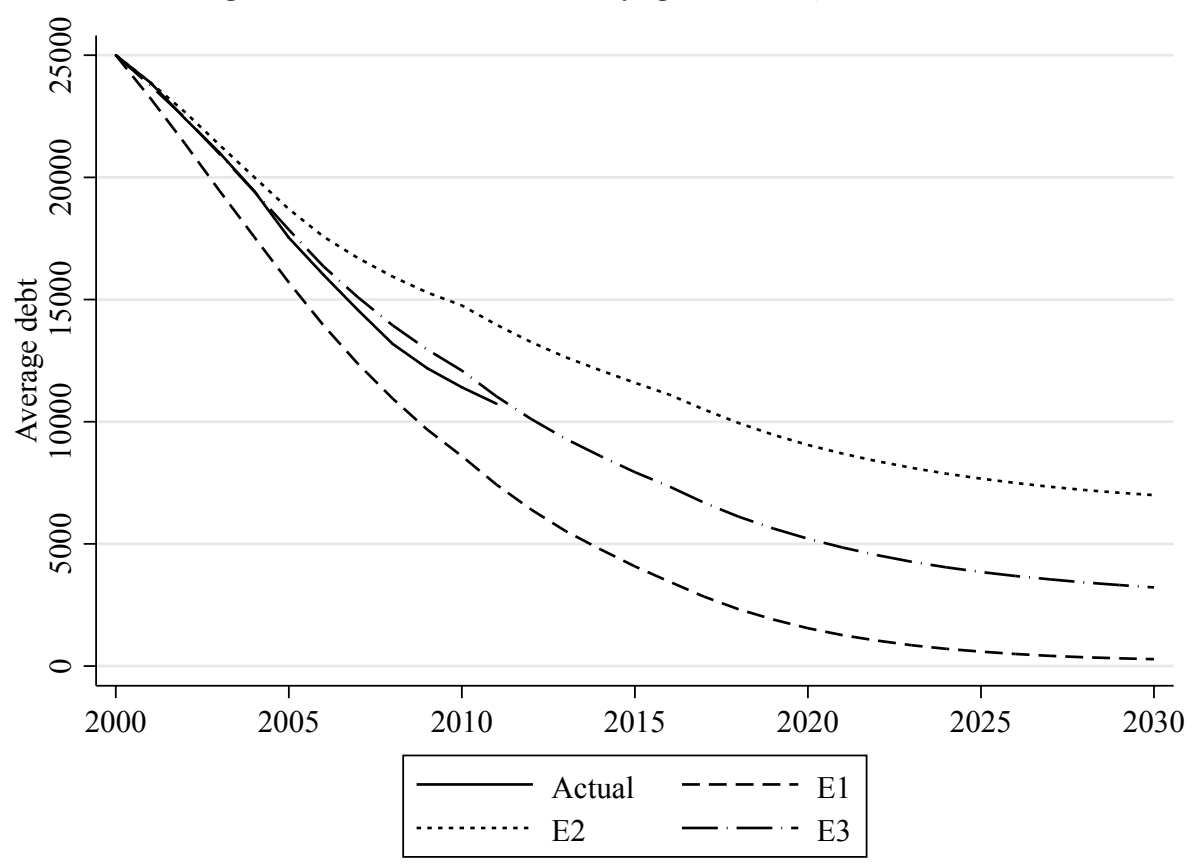


Table 6: Subsidy calculations

\begin{tabular}{lccc}
\hline & E1 & E2 & E3 \\
\hline Male and female university graduates & & & \\
L1 & $21 \%$ & $36 \%$ & $26 \%$ \\
L2 & $15 \%$ & $30 \%$ & $21 \%$ \\
L3 & $13 \%$ & $27 \%$ & $20 \%$ \\
\hline Male university graduates & & \\
L1 & $12 \%$ & $18 \%$ & $14 \%$ \\
L2 & $9 \%$ & $15 \%$ & $11 \%$ \\
L3 & $8 \%$ & $14 \%$ & $11 \%$ \\
\hline Female university graduates & & & \\
L1 & $28 \%$ & $51 \%$ & $36 \%$ \\
L2 & $20 \%$ & $42 \%$ & $29 \%$ \\
L3 & $17 \%$ & $36 \%$ & $27 \%$ \\
\hline
\end{tabular}




\section{References}

Abowd, J. and Card, D. (1989). On the Covariance Structure of Earnings and Hours Changes. Econometrica 57: 411-445.

ABS (2006). 2005-06 Survey of Income and Housing Confidentialised Unit Record File. Technical Report, Commonwealth of Australia.

Baker, M. (1997). Growth-Rate Heterogeneity and the Covariance Structure of LifeCycle Earnings. Journal of Labor Economics 15: 338-375.

Baker, M. and Solon, G. (2003). Earnings Dynamics and Inequality among Canadian Men, 1976-1992: Evidence from Longitudinal Income Tax Records. Journal of Labor Economics 21: 289-321.

Browning, M., Ejrnaes, M. and Alvarez, J. (2010). Modelling Income Processes with Lots of Heterogeneity. Review of Economic Studies 77: 1353-1381.

Caldwell, S. (1996). Health, Wealth, Pensions and Life Paths: The CORSIM Dynamic Microsimulation Model. In Harding, A. (ed.), Microsimulation and Public Policy. Elsevier, 505-522.

Cappellari, L. (2004). The Dynamics of Inequality of Italian Men's Earnings: LongTerm Changes or Transitory Fluctuations? Journal of Human Resources 39: 475499.

Chapman, B. (2006). Government Managing Risk: Income Contingent Loans for Social and Economic Progress. London: Routledge.

Chapman, B. and Liu, A. (forthcoming). Repayment Burdens of Student Loans for Vietnamese Higher Education. Economics of Education Review .

Chapman, B. and Lounkaew, K. (2010). Income Contingent Student Loans for Thailand: Alternatives Compared. Economics of Education Review 29: 695-709. 
Dickens, R. (2000). The Evolution of Individual Male Earnings in Great Britain: 197595. Economic Journal 110: 27-49.

Flannery, D. and O'Donoghue, C. (2011). The Life-cycle Impact of Alternative Higher Education Finance Systems in Ireland. Economic and Social Review 42: 237-270.

Gary-Bobo, R. and Trannoy, A. (2013). Optimal Student Loans and Graduate Tax under Moral Hazard and Adverse Selection. CESifo Working Paper No. 4279.

Greene, W. H. (2012). Econometric Analysis. New Jersey: Prentice Hall.

Guvenen, F. (2009). An Empirical Investigation of Labor Income Processes. Review of Economic Dynamics 12: 58-79.

Haider, S. (2001). Earnings Instability and Earnings Inequality of Males in the United States: 1967-1991. Journal of Labor Economics 19: 799-836.

Harding, A. (1995). Financing Higher Education: An Assessment of Income-Contingent Loan Options and Repayment Patterns Over the Life Cycle. Education Economics 3: $173-203$.

Harris, A. and Sabelhaus, J. (2003). Projecting Longitudinal Earnings Patterns for Long-Run Policy Analysis. Technical Paper Series, Congressional Budget Office, Washington D.C.

Higgins, T. (2011). Implications of Earnings Model Complexity to Costing Income Contingent Loans. Unpublished Working Paper.

Holmer, M., Janney, A. and Cohen, B. (2010). PENSIM Overview. U.S. Department of Labor Employee Benefits Security Administration Office of Policy and Research, Policy Simulation Group.

Hsiao, C. (2003). Analysis of Panel Data. Cambridge: Cambridge University Press. 
Kalwij, A. and Alessie, R. (2007). Permanent and Transitory Wages of British Men, 1975-2001: Year, Age and Cohort Effects. Journal of Applied Econometrics 22: 10631093.

Lillard, L. A. and Willis, R. J. (1978). Dynamic Aspets of Earning Mobility. Econometrica 46: 985-1012.

MaCurdy, T. E. (1982). The Use of Time Series Processes to Model the Error Structure of Earnings in a Longitudinal Data Analysis. Journal of Econometrics 18: 83-114.

Meghir, C. and Pistaferri, L. (2004). Income Variance Dynamics and Heterogeneity. Econometrica 72: 1-32.

Migali, G. (2012). Funding Higher Education and Wage Uncertainty: Income Contingent Loan Versus Mortgage Loan. Economics of Education Review 31: 871-889.

Moffitt, R. and Gottschalk, P. (2002). Trends in the Transitory Variance of Earnings in the United States. Economic Journal 112: 68-73.

Norton, A. (2013). Mapping Australian Higher Education, 2013 Version. Report, Grattan Institute.

O’Donoghue, C. (2001). Dynamic Microsimulation: A Methodological Survey. Unpublished Working Paper.

Swan, N. (2006). Problems in Dynamic Modeling of Individual Incomes. Swedish Conference on Microsimulation, Stockholm.

Toder, R., Favreault, M., O’Hare, J., Rogers, D., Sammartino, F., Smith, K., Smetters, K. and Rust, J. (2000). Long Term Model Development for Social Security Policy Analysis. The Urban Institute, Washington D.C. 